\title{
Pharmacotherapy of Depression
}




\section{PHARMACOTHERAPY OF DEPRESSION}

Edited by

Domenic A. Ciraulo, mD

Boston University School of Medicine, Boston, MA Richard I. SHADER, MD

Tufts University School of Medicine, Boston, MA 
(C) 2004 Springer Science+Business Media New York

Originally published by Humana Press Inc. in 2004

\section{humanapress.com}

All rights reserved. No part of this book may be reproduced, stored in a retrieval system, or transmitted in any form or by any means, electronic, mechanical, photocopying, microfilming, recording, or otherwise without written permission from the Publisher.

All articles, comments, opinions, conclusions, or recommendations are those of the author(s), and do not necessarily reflect the views of the publisher.

Due diligence has been taken by the publishers, editors, and authors of this book to ensure the accuracy of the information published and to describe generally accepted practices. The contributors herein have carefully checked to ensure that the drug selections and dosages set forth in this text are accurate in accord with the standards accepted at the time of publication. Notwithstanding, as new research, changes in government regulations, and knowledge from clinical experience relating to drug therapy and drug reactions constantly occurs, the reader is advised to check the product information provided by the manufacturer of each drug for any change in dosages or for additional warnings and contraindications. This is of utmost importance when the recommended drug herein is a new or infrequently used drug. It is the responsibility of the health care provider to ascertain the Food and Drug Administration status of each drug or device used in their clinical practice. The publisher, editors, and authors are not responsible for errors or omissions or for any consequences from the application of the information presented in this book and make no warranty, express or implied, with respect to the contents in this publication.

This publication is printed on acid-free paper. @

ANSI Z39.48-1984 (American National Standards Institute)

Permanence of Paper for Printed Library Materials.

Production Editor: Robin B. Weisberg.

Cover design by Patricia F. Cleary.

Authorization to photocopy items for internal or personal use, or the internal or personal use of specific clients, is granted by Springer Science+Business Media, LLC.

provided that the base fee of US $\$ 25.00$ per copy is paid directly

to the Copyright Clearance Center at 222 Rosewood Drive, Danvers, MA 01923. For those organizations that have been granted a photocopy license from the CCC, a separate system of payment has been arranged and is acceptable to Springer Science+Business Media, LLC.

The fee code for users of the Transactional Reporting Service is: [1-58829-139-1/04 \$25.00].

\section{ISBN 978-1-4757-6172-6}

Library of Congress Cataloging-in-Publication Data

Pharmacotherapy of depression / edited by Domenic A. Ciraulo, Richard I. Shader.

$$
\text { p. ; cm. }
$$

Includes bibliographical references and index.

Additional material to this book can be downloaded from http://extras.springer.com.

ISBN 978-1-4757-6172-6 ISBN 978-1-59259-792-5 (eBook)

DOI 10.1007/978-1-59259-792-5

1. Depression, Mental--Chemotherapy. 2. Antidepressants.

[DNLM: 1. Depressive Disorder--drug therapy. 2. Bipolar Disorder--drug therapy. 3. Depressive Disorder--complications. WM 171 P5364 2004] I. Ciraulo, Domenic A. II. Shader, Richard I., 1935-

RC537.P465 2004

$616.85 ' 27061--d c 22$ 


\section{Preface}

For many years, we have taught clinical psychopharmacology to residents in psychiatry, neurology, and medicine, as well as to medical students, nurses, psychologists, counselors, and social workers. We have also maintained active clinical practices and research programs. It is our hope that these experiences have produced a book that will serve as a resource in antidepressant therapy for clinicians from many different disciplines.

The purpose of Pharmacotherapy of Depression is to provide a comprehensive overview of antidepressant therapy for clinicians. The contents have evolved from our years of seminars, lectures, and case discussions with our trainees and from our continuing medical education programs. We have tried to provide sufficient depth in reviews of the research literature to support clinical recommendations without burdening the reader with information that has little relevance to the clinical use of antidepressants.

We are indebted to the outstanding clinician scientists who have contributed to this volume and to our students who have guided us in its development. We hope that the reader will find that the final product represents a solid foundation for clinicians who are, or will be, prescribing antidepressants. It comes very close to replicating the formal didactics that our trainees experience. Although in practice we supplement this with intensive supervision of patient management, we hope that Pharmacotherapy of Depression will stand alone as a guide to the use of medications for the treatment of depressive illness.

Domenic A. Ciraulo, MD

Richard I. Shader, MD 


\section{Contents}

Preface $\mathrm{v}$

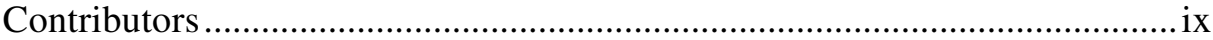

Value-Added eBook/PDA ....................................................................

1 Biological Theories of Depression and Implications for Current and New Treatments

David J. Goldstein and William Z. Potter

2 Clinical Pharmacology and Therapeutics of Antidepressants

Domenic A. Ciraulo, Lucy Tsirulnik-Barts, Richard I. Shader, and David J. Greenblatt

3 Antidepressant Treatment of Geriatric Depression

James F. Evans, Domenic A. Ciraulo, Meghan F. Zysik, Richard I. Shader, and Carl Salzman

4 Treatment of Bipolar Depression

Robert T. Dunn and Robert M. Post

5 Treatment of Depression in Psychotic Disorders

Donald C. Goff

6 Substance Abuse and Depression

John A. Renner, Jr., Jeffrey D. Baxter, and Domenic A. Ciraulo

7 Depressive Disorders in the Context of HIV/AIDS:

Prevalence and Treatment.

Jori A. Berger-Greenstein, Stephen Brady, David Spiggle, Deborah J. Brief, and Terence M. Keane

8 Diagnosis and Treatment of Depression During Pregnancy and Lactation 265

Ofra Sarid-Segal, Jon A. Ciraulo, Richard I. Shader

9 Antidepressant Treatments in Posttraumatic Stress Disorder 297

Janet E. Osterman and Brandon Z. Erdos

10 Antidepressant Therapy in Children and Adolescents:

An Overview for the Generalist

Domenic A. Ciraulo, Danielle M. Ciraulo, and Glenn Saxe

Index 337 


\section{CONTRIBUTORS}

JeFreey D. BAXTER, MD $・$ Division of Psychiatry, Boston University School of Medicine, Boston, MA

Jori A. Berger-GreensteIn, PhD • Division of Psychiatry, Boston University School of Medicine, Boston, MA

StePhen Brady, $\mathrm{PhD} \cdot$ Division of Psychiatry, Boston University School of Medicine, Boston, MA

DeBorah J. BRIEF, PhD • Division of Psychiatry, Boston University School of Medicine, Boston, MA

Danielle M. Ciraulo, mS • Division of Psychiatry, Boston University School of Medicine, Boston, MA

Domenic A. Ciraulo, MD • Division of Psychiatry, Boston University School of Medicine, Boston, MA

Jon A. Ciraulo, Ba • Division of Psychiatry, Boston University School of Medicine, Boston, MA

Robert T. Dunn, MD, PhD - Department of Psychiatry, Harvard Medical School, Boston, and Cambridge Hospital, Cambridge, MA

Brandon Z. ERdos, MD • Division of Psychiatry, Boston University School of Medicine, Boston, MA

James F. Evans, MD $\bullet$ Department of Psychiatry, Quincy Medical Center, Quincy, and Division of Psychiatry, Boston University School of Medicine, Boston, MA

Donald C. GofF, MD $\bullet$ Schizophrenia Program, Massachusetts General Hospital, Boston, MA

DAVID J. GolDSTEIN, MD, $\mathrm{PhD} \bullet P R N$ Consulting and Department of Pharmacology and Toxicology, Indiana University School of Medicine, Indianapolis, IN

David J. GreEnblatt, MD $\bullet$ Department of Pharmacology and Experimental Therapeutics, Tufts University School of Medicine, Boston, MA

Terence M. Keane, PhD $・$ Division of Psychiatry, Boston University School of Medicine, Boston, MA

Janet E. Osterman, MD $・$ Division of Psychiatry, Boston University School of Medicine, Boston, MA

Robert M. Post, MD $•$ National Institute of Mental Health, National Institutes of Health, Bethesda, MD

William Z. PotTer, MD, PhD • Neuroscience Division, Eli Lilly and Co., Indianapolis, IN

John A. Renner, JR., MD • Department of Veterans Affairs, Boston, MA 
Carl Salzman, MD $\bullet$ Department of Psychiatry, Harvard Medical School, Boston, $M A$

Ofra SARID-Segal, Md $•$ Division of Psychiatry, Boston University School of Medicine, Boston, MA

Glenn SAXE, MD • Division of Psychiatry, Boston University School of Medicine, Boston, MA

RichaRd I. SHADER, MD - Division of Pharmacology and Experimental Therapeutics, Tufts University School of Medicine, Boston, MA

David SPIGgLe, MD • Department of Psychiatry, Massachusetts General Hospital, Boston, MA

LuCy TsIRULNIK-BARTS, MD • Division of Psychiatry, Boston University School of Medicine, Boston, MA

Meghan F. Zysik, Ba • Division of Psychiatry, Boston University School of Medicine, Boston, MA 


\section{Value-Added eBook/PDA}

This book is accompanied by a value-added CD-ROM that contains an Adobe eBook version of the volume you have just purchased. This eBook can be viewed on your computer, and you can synchronize it to your PDA for viewing on your handheld device. The eBook enables you to view this volume on only one computer and PDA. Once the eBook is installed on your computer, you cannot download, install, or e-mail it to another computer; it resides solely with the computer to which it is installed. The license provided is for only one computer. The eBook can only be read using Adobe ${ }^{\circledR}$ Reader $^{\circledR} 6.0$ software, which is available free from Adobe Systems Incorporated at www.Adobe.com. You may also view the eBook on your PDA using the Adobe ${ }^{\circledR}$ PDA Reader ${ }^{\circledR}$ software that is also available free from Adobe.com.

You must follow a simple procedure when you install the eBook/PDA that will require you to connect to the Humana Press website in order to receive your license. Please read and follow the instructions below:

1. Download and install Adobe ${ }^{\circledR}$ Reader $^{\circledR} 6.0$ software

You can obtain a free copy of Adobe ${ }^{\circledR}$ Reader $^{\circledR} 6.0$ software at www.adobe.com

*Note: If you already have Adobe ${ }^{\circledR}$ Reader ${ }^{\circledR} 6.0$ software, you do not need to reinstall it.

2. Launch Adobe ${ }^{\circledR}$ Reader ${ }^{\circledR} 6.0$ software

3. Install eBook: Insert your eBook CD into your CD-ROM drive

PC: Click on the "Start" button, then click on "Run"

At the prompt, type "d:lebookinstall.pdf" and click "OK"

*Note: If your CD-ROM drive letter is something other than d: change the above command accordingly.

MAC: Double click on the "eBook CD" that you will see mounted on your desktop.

Double click "ebookinstall.pdf"

4. Adobe ${ }^{\circledR}$ Reader $^{\circledR} 6.0$ software will open and you will receive the message

"This document is protected by Adobe DRM" Click "OK"

*Note: If you have not already activated Adobe ${ }^{\circledR}$ Reader ${ }^{\circledR} 6.0$ software, you will be prompted to do so. Simply follow the directions to activate and continue installation.

Your web browser will open and you will be taken to the Humana Press eBook registration page. Follow the instructions on that page to complete installation. You will need the serial number located on the sticker sealing the envelope containing the CD-ROM.

If you require assistance during the installation, or you would like more information regarding your eBook and PDA installation, please refer to the eBookManual.pdf located on your CD. If you need further assistance, contact Humana Press eBook Support by e-mail at ebooksupport@ humanapr.com or by phone at 973-256-1699.

*Adobe and Reader are either registered trademarks or trademarks of Adobe Systems Incorporated in the United States and/or in other countries. 